\title{
Evaluation of GaN Transistors Having Two Different Gate-Lengths for Class-S PA Design
}

\author{
Jun-Chul Park ${ }^{1} \cdot$ Chan-Sei Yoo ${ }^{2}$ Dongsu Kim³ $\cdot$ Woo-Sung Lee ${ }^{2}$ Jong-Gwan Yook ${ }^{1, *}$
}

\begin{abstract}
This paper presents a characteristic evaluation of commercial gallium nitride $(\mathrm{GaN})$ transistors having two different gate-lengths of $0.4-$ $\mu \mathrm{m}$ and $0.25-\mu \mathrm{m}$ in the design of a class-S power amplifier (PA). Class-S PA is operated by a random pulse-width input signal from band-pass delta-sigma modulation and has to deal with harmonics that consider quantization noise. Although a transistor having a short gate-length has an advantage of efficient operation at higher frequency for harmonics of the pulse signal, several problems can arise, such as the cost and export license of a $0.25-\mu \mathrm{m}$ transistor. The possibility of using a $0.4-\mu \mathrm{m}$ transistor on a class-S PA at $955 \mathrm{MHz}$ is evaluated by comparing the frequency characteristics of GaN transistors having two different gate-lengths and extracting the intrinsic parameters as a shape of the simplified switch-based model. In addition, the effectiveness of the switch model is evaluated by currentmode class-D (CMCD) simulation. Finally, device characteristics are compared in terms of current-mode class-S PA. The analyses of the CMCD PA reveal that although the efficiency of $0.4-\mu \mathrm{m}$ transistor decreases more as the operating frequency increases from $955 \mathrm{MHz}$ to 3,500 $\mathrm{MHz}$ due to the efficiency limitation at the higher frequency region, it shows similar power and efficiency of $41.6 \mathrm{dBm}$ and $49 \%$, respectively, at $955 \mathrm{MHz}$ when compared to the $0.25-\mu \mathrm{m}$ transistor.
\end{abstract}

Key Words: Cass-S amplifier, Current-Mode Amplifier, Gallium Nitride (GaN), Gate-Length, Switch-Mode Amplifier.

\section{INTRODUCTION}

Enhancement of the efficiency of the power amplifier (PA) at a wide dynamic range is important for modern communication signals. Various groups have studied several efficiency enhancement techniques, such as Doherty [1-4], envelope tracking [5, 6], envelope elimination and restoration [7], and linear amplification with nonlinear components [8]. The class-S amplifier and the concept of digital amplifier based on the delta-sigma modulator (DSM) and switch-mode PA (SMPA) with push-pull structure, is now being intensively investigated because the class-S system has potential to provide high linearity and efficiency $[9,10]$.

However, the overall characteristics of a PA, such as the output power, efficiency, and operating frequency, are basically decided by the transistor. Therefore, the selection of the transistor is important in the design of a PA. The SMPA, in particular, requires a transistor capable of high power and speed when working in the range of radio frequencies $(\mathrm{RF})$. The purely digital operation of the class-S PA also requires a fast switching transistor, and several studies on class-S PA using gallium nitride $(\mathrm{GaN})$ transistor are in progress.

The increased demand for high power and frequency has led to intensive study and wide use of $\mathrm{GaN}$ in many fields. GaN has excellent characteristics such as a wide band gap, high breakdown voltage, high thermal conductivity, and high electron saturation velocity [11-15]. Above all, the high power capability of GaN

\footnotetext{
Manuscript received June 9, 2014 ; Revised August 19, 2014 ; Accepted September 4, 2014. (ID No. 20140609-024J)

${ }^{1}$ Electrical and Electronic Engineering Department, Yonsei University, Seoul, Korea.

${ }^{2}$ Electronic Materials \& Device Research Center, Korea Electronics Technology Institute, Seongnam, Korea.

${ }^{3}$ Packaging Research Center, Korea Electronics Technology Institute, Seongnam, Korea.

*Corresponding Author: Jong-Gwan Yook (e-mail: jgyook@yonsei.ac.kr)
}

This is an Open-Access article distributed under the terms of the Creative Commons Attribution Non-Commercial License (http://creativecommons.org/licenses/ by-nc/3.0) which permits unrestricted non-commercial use, distribution, and reproduction in any medium, provided the original work is properly cited.

(c) Copyright The Korean Institute of Electromagnetic Engineering and Science. All Rights Reserved. 
enables low intrinsic capacitance and fast switching operation [16, $17]$, and many studies on transistor structure are now actively investigating ways to achieve efficient operation at higher frequency by reducing gate-length of transistor. A $0.4-\mu \mathrm{m}$ transistor is now in wide use and a $0.25-\mu \mathrm{m}$ transistor is also available on the market. However, although a transistor with a short gate-length will clearly show better performance at higher frequency, some problems still limit the use of the $0.25-\mu \mathrm{m}$ transistor, such as its cost and export license.

In this paper, the possibility of using a transistor having a 0.4$\mu \mathrm{m}$ gate-length on a class-S PA at $955 \mathrm{MHz}$ in comparison to a $0.25-\mu \mathrm{m}$ transistor is evaluated by examining the small-signal characteristics, such as maximum available gain as well as current gain, using a commercial $\mathrm{GaN}$ transistor having two different gate-lengths and similar output power. The intrinsic parameters of the GaN transistor are extracted as the simplified switch-based model and the basic RF characteristics of the simplified switch model and behavior transistor model are described by load-pull simulation. The device characteristics are analyzed in terms of current-mode class-D (CMCD) and current-mode class-S (CMCS) PA structures. This paper is organized as shown in Fig. 1.

\section{BASIC CHARACTERISTICS OF THE GAN TRANSISTOR}

Generally, the gate-width and gate-length of a transistor are related to an output power and a maximum operating frequency,

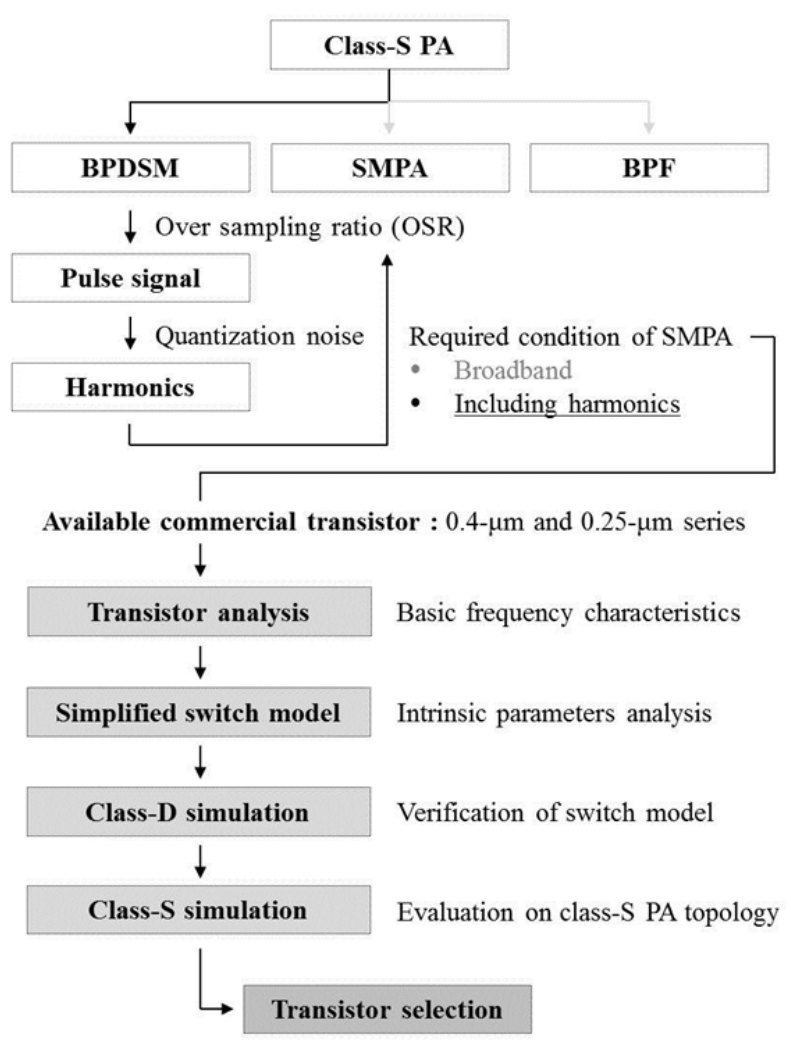

Fig. 1. Simplified evaluation process of gallium nitride $(\mathrm{GaN})$ transistors for class-S power amplifier (PA). BPDSM = band-pass delta-sigma modulation, $\mathrm{SMPA}=$ switch-mode $\mathrm{PA}, \mathrm{BPF}=$ band-pass filter. respectively. As high frequency operation of transistors is required in many fields, research has mainly focused on reducing the transistor gate-length. Considering this trend, the simulation models by CREE Inc., which utilize $\mathrm{GaN}$ transistors with two different gate lengths of $0.4-\mu \mathrm{m}$ and $0.25-\mu \mathrm{m}$, are used to evaluate the characteristics of the transistor in terms of $\mathrm{CMCD}$ and CMCS PA. The effect of transistor size is examined by using transistors with various gate dimensions in each case. Note that the gate-widths of these transistors are unequal and specific width is used for the two gate-lengths, because these transistors are commercial transistors, used to select an adequate one for CMCS $\mathrm{PA}$. This section introduces the DC and RF characteristics of transistors to confirm the frequency responses according to the gate-length for harmonics of a pulse-shaped input signal.

\section{DC Characteristics: $f_{T}$ and $f_{\max }$}

The operation of the transistor from the perspective of frequency variation can be simply shown as a unity current gain frequency $\left(f_{T}\right)$ and a unity power gain frequency $\left(f_{\max }\right) \cdot f_{T}$ is defined for the condition where the output is AC shorted, and $f_{\max }$ is the frequency at which the maximum power gain equals 1 and is defined with its input and output ports conjugate-matched for maximum power transfer. These parameters are varied according to the bias condition and extracted by using scattering parameters at a desired bias voltage. With different drain voltages, $f_{T}$ and $f_{\max }$ of the $0.4-\mu \mathrm{m}$ and $0.25-\mu \mathrm{m} \mathrm{GaN}$ transistors are shown in Figs. 2 and 3. Several drain biases for the $0.4-\mu \mathrm{m}$ and $0.25-\mu \mathrm{m}$ $\mathrm{GaN}$ transistors are used from the low voltage of $10 \mathrm{~V}$ to the suggested high voltage for maximum output power, which are 28 $\mathrm{V}$ and $40 \mathrm{~V}$, respectively. As the drain voltage increases, $f_{T}$ and $f_{\max }$ of each transistor are also increased. As expected, the transistor with the short gate-length shows a higher frequency

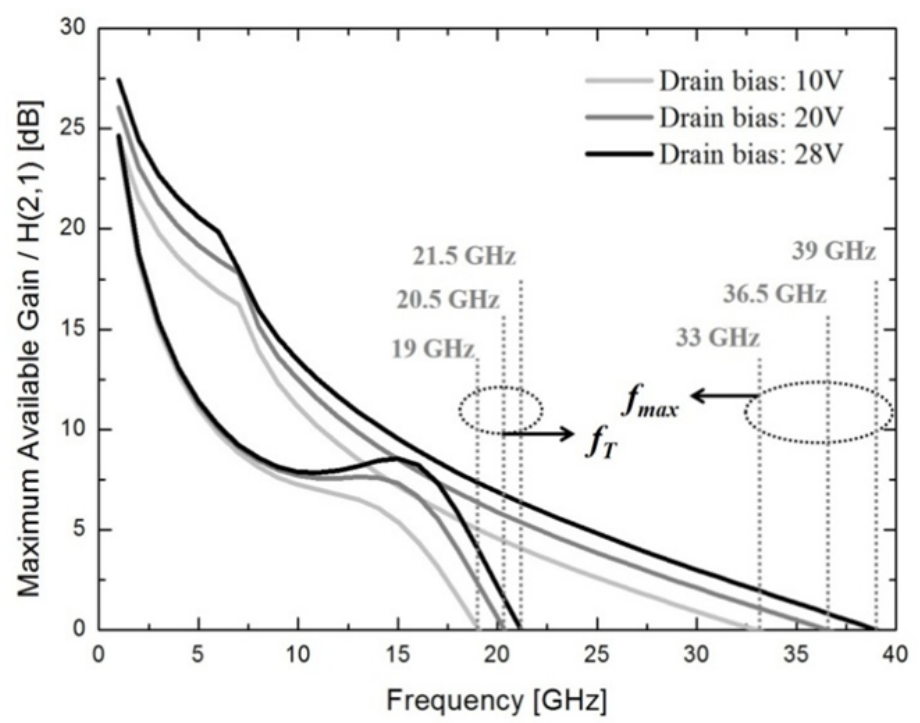

Fig. 2. Simulated maximum available gain and current gain $\mathrm{dB}(\mathrm{H}(2,1))$ as a function of frequency for gallium nitride $(\mathrm{GaN})$ transistor with $0.4-\mu \mathrm{m}$ gate-length. 


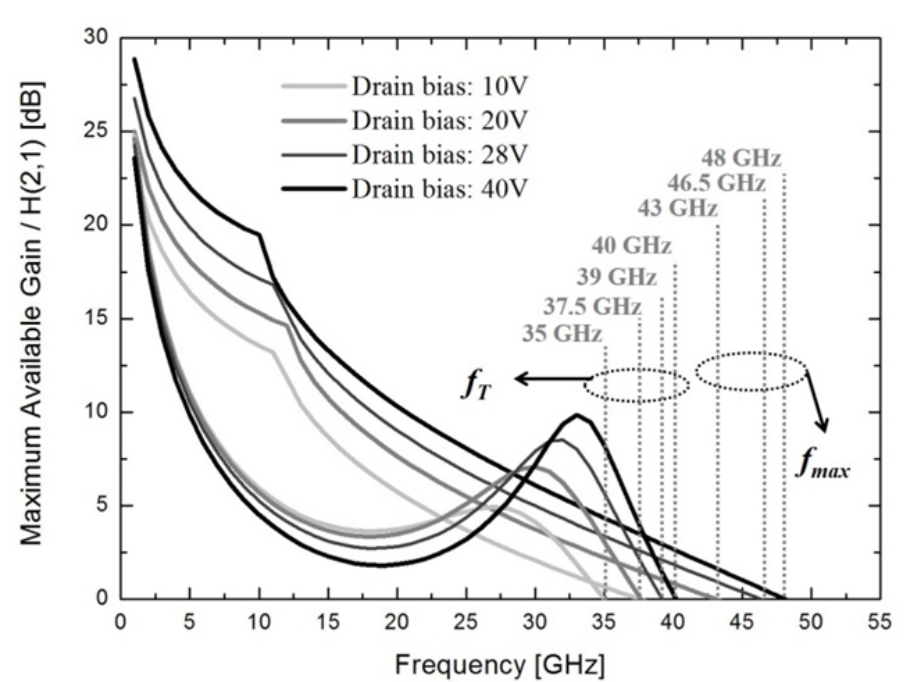

Fig. 3. Simulated maximum available gain and current gain $\mathrm{dB}(\mathrm{H}(2,1))$ as a function of frequency for gallium nitride $(\mathrm{GaN})$ transistor with $0.25-\mu \mathrm{m}$ gate-length.

Table 1. $f_{T}$ and $f_{\max }$ characteristics of $\mathrm{GaN}$ transistors with a gate-length of $0.4-\mu \mathrm{m}$ and $0.25-\mu \mathrm{m}$ according to the drain bias voltages

\begin{tabular}{cccc}
\hline $\begin{array}{c}\text { Gate-length } \\
(\mu \mathrm{m})\end{array}$ & $\begin{array}{c}V_{D D} \\
(\mathrm{~V})\end{array}$ & $\begin{array}{c}f_{T} \\
(\mathrm{GHz})\end{array}$ & $\begin{array}{c}F_{\max } \\
(\mathrm{GHz})\end{array}$ \\
\hline \multirow{3}{*}{0.4} & 10 & 19 & 33 \\
& 20 & 20.5 & 36.5 \\
& 28 & 21.5 & 39 \\
\hline \multirow{2}{*}{0.25} & 10 & 35 & 37.5 \\
& 20 & 37.5 & 43 \\
& 28 & 39 & 46.5 \\
& 40 & 40 & 48 \\
\hline
\end{tabular}

characteristic and it is appropriate for designs that consider higher harmonic frequencies. Table 1 summarizes the $f_{T}$ and $f_{\max }$ characteristics of $\mathrm{GaN}$ transistors with gate-lengths of $0.4-\mu \mathrm{m}$ and $0.25-\mu \mathrm{m}$ according to the drain bias voltages.

\section{RF Characteristics: Load-Pull Simulation}

In general, large signal characteristics of transistors can be extracted by load-pull simulation. For the SMPA design, the performance of a class-D PA can also be obtained by load-pull

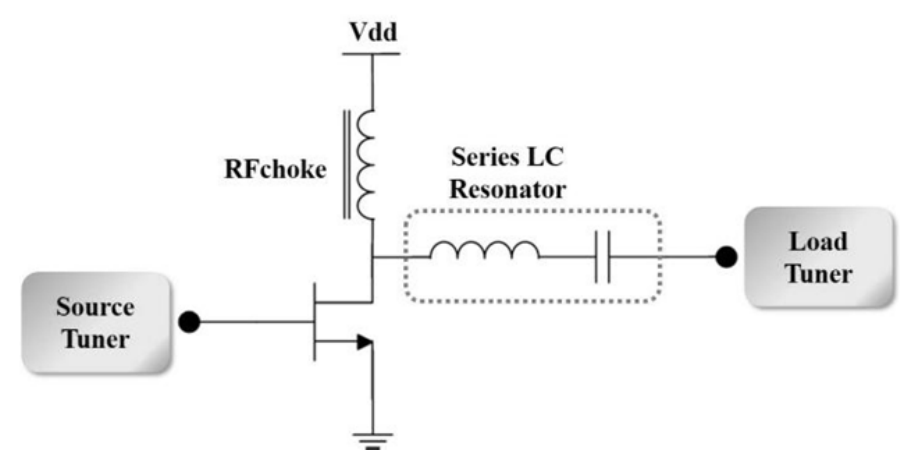

Fig. 4. Load-pull simulation setup based on the class-D structure.

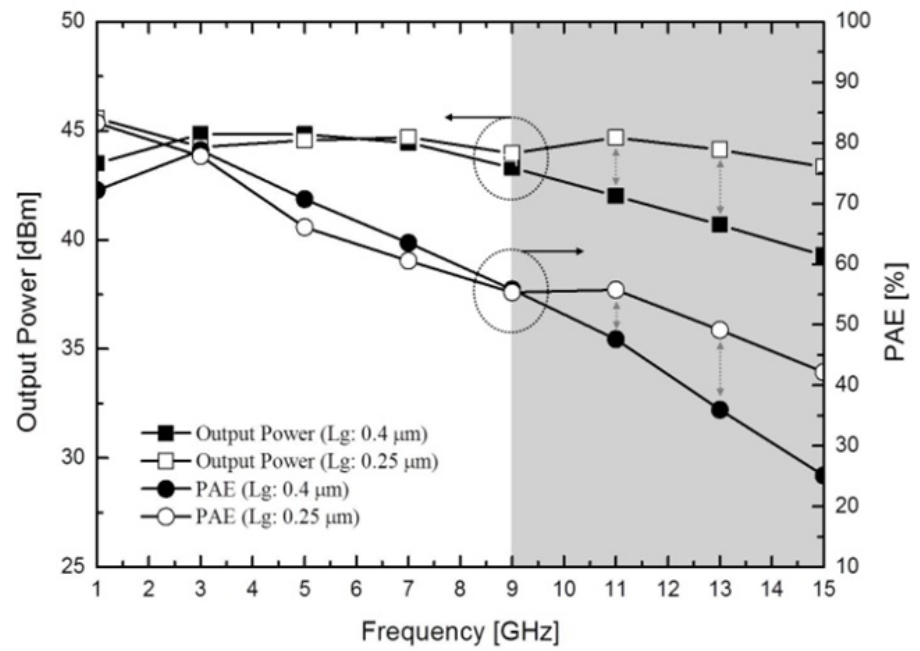

Fig. 5. Load-pull simulation of the output power and power-added efficiency (PAE) using $0.4-\mu \mathrm{m}$ and $0.25-\mu \mathrm{m}$ gallium nitride $(\mathrm{GaN})$ transistors.

simulation with a proper harmonic termination, as shown in Fig. 4. In this conventional class-D topology, the series LC resonator resonates on an operating fundamental frequency, and thereby terminates harmonics as an open condition. Note that in order to achieve proper class-D operation and have open-state harmonics, the effects of $C_{d s}$ and $C_{g d}$ of transistor must always be considered because they tend to provide low impedance shunt paths. In this load-pull simulation, the reactance component of shunt capacitances can be compensated by a load tuner.

From the simulation in the frequency range between $1 \mathrm{GHz}$ to $15 \mathrm{GHz}$, the output power and power-added efficiency (PAE) characteristics of the transistor are simulated and described in Fig. 5. $\mathrm{GaN}$ transistors are used that have gate-lengths of $0.4-\mu \mathrm{m}$ and $0.25-\mu \mathrm{m}$ and maximum power outputs of $30 \mathrm{~W}$ and $25 \mathrm{~W}$, respectively. Although the results are similar in the frequency ranges under $9 \mathrm{GHz}$, the performance differences of the two transistors become obvious as frequency increases. Thus, the device with a short gate-length is clearly advantageous for high frequency applications.

\section{SIMPLIFIED SWITCH-BASED MODEL OF A GAN TRANSISTOR}

The conventional linear amplifiers such as class- $\mathrm{A}, \mathrm{AB}, \mathrm{B}$, and $\mathrm{C}$ are generally designed by using the behavioral model from the manufacturer or by measuring source and load impedances. However, this large signal model is complicated and needed a lot of time to simulate, whereas the SMPA operates in only two states, the on- and off-states. Therefore, the simplified switchbased model is sufficient to predict the switching operation of CMCD PA and has been studied by several groups [18-20]. The simplified switch-based model in the desired bias condition can be extracted by small-signal modeling of FET, which was pro- 
Table 2. Summary of the intrinsic parameters of gallium nitride $(\mathrm{GaN})$ transistors with a gate-length of $0.4-\mu \mathrm{m}$ and $0.25-\mu \mathrm{m}$ according to the different gate-widths

\begin{tabular}{|c|c|c|c|c|c|c|c|c|}
\hline \multirow[b]{2}{*}{$W_{g}$} & \multirow[b]{2}{*}{$(\mathrm{mm})$} & \multicolumn{4}{|c|}{$L_{g}=0.4-\mu \mathrm{m}$} & \multicolumn{3}{|c|}{$L_{g}=0.25-\mu \mathrm{m}$} \\
\hline & & 2.16 & 3.6 & 7.2 & 14.4 & 1.2 & 4.8 & 14.4 \\
\hline Power & $(\mathrm{W})$ & 8 & 15 & 30 & 60 & 6 & 25 & 70 \\
\hline$C_{g s}$ & $(\mathrm{pF})$ & 2.66 & 4.43 & 8.86 & 17.71 & 1.32 & 5.27 & 15.81 \\
\hline$C_{d s}$ & $(\mathrm{pF})$ & 0.52 & 0.86 & 1.73 & 3.46 & 0.35 & 1.38 & 4.14 \\
\hline$C_{g d}$ & $(\mathrm{pF})$ & 0.27 & 0.45 & 0.91 & 1.82 & 0.2 & 0.8 & 2.4 \\
\hline$R_{i}$ & $(\Omega)$ & 1.2 & 0.7 & 0.3 & 0.18 & 1.3 & 0.34 & 0.11 \\
\hline Ron & $(\Omega)$ & 1.6 & 1 & 0.5 & 0.25 & 2.3 & 0.6 & 0.2 \\
\hline \multicolumn{9}{|c|}{ Converted to millimeters } \\
\hline Porwer & $(\mathrm{W} / \mathrm{mm})$ & 3.7 & 4.17 & 4.17 & 4.17 & 5 & 5.21 & 4.86 \\
\hline$C_{g s}$ & $(\mathrm{pF} / \mathrm{mm})$ & 1.23 & 1.23 & 1.23 & 1.23 & 1.1 & 1.1 & 1.1 \\
\hline$C_{d s}$ & $(\mathrm{pF} / \mathrm{mm})$ & 0.24 & 0.24 & 0.24 & 0.24 & 0.29 & 0.29 & 0.29 \\
\hline$C_{g d}$ & $(\mathrm{pF} / \mathrm{mm})$ & 0.13 & 0.13 & 0.13 & 0.13 & 0.17 & 0.17 & 0.17 \\
\hline$R_{i}$ & $(\Omega \mathrm{mm})$ & 2.59 & 2.52 & 2.16 & 2.59 & 1.56 & 1.63 & 1.58 \\
\hline$R_{o n}$ & $(\Omega \mathrm{mm})$ & 3.46 & 3.6 & 3.6 & 3.6 & 2.76 & 2.88 & 2.88 \\
\hline
\end{tabular}

posed in 1988 by Dambrine et al. [21]. Fig. 6 briefly shows the modeling procedure of the simplified switch-based model. The on- and off-resistances are calculated by the inverse number of gradient between voltage and current value in the I-V curve of transistor. The intrinsic capacitances, $C_{g r}, C_{d s}$, and $C_{g d,}$, and resistance $R_{i}$ can be calculated by S-parameters.

The simplified switch-based model of $\mathrm{GaN}$ transistor is composed of the calculated values, as shown in Fig. 7. According to the input voltage level, the switch in this model is set with $R_{o n}$ for on-state and $R_{\text {off }}$ for off-state. Table 2 summarizes the intrinsic parameters of $\mathrm{GaN}$ transistors with two different gatelengths with different gate-width, which are related to the available output power level. Although the transistor size is not exactly matched in the two transistors with different gate-length, the intrinsic parameters can be converted into per unit length quan-

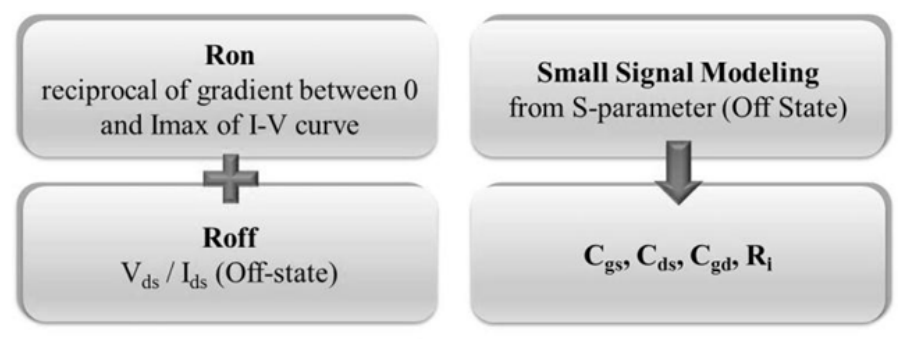

Simplified switch-based GaN HEMT model

Fig. 6. The procedure for simplified switch-based modeling. $\mathrm{GaN}=$ gallium nitride, HEMT = high-electron mobility transistor.

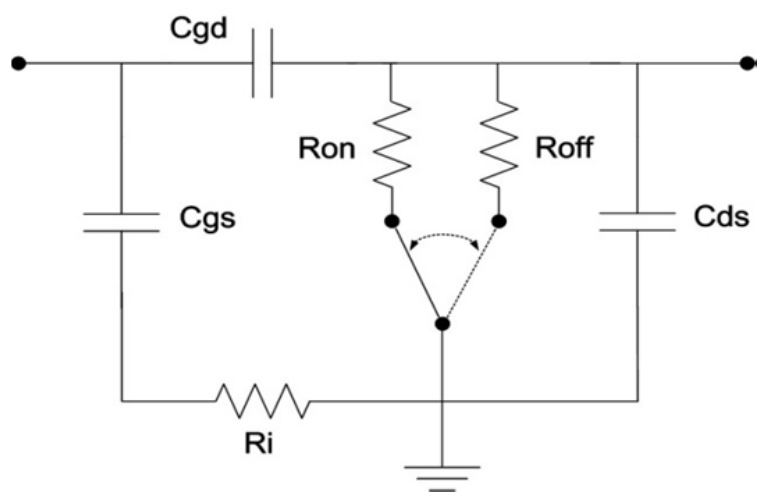

Fig. 7. Simplified switch-based model of gallium nitride $(\mathrm{GaN})$ transistor.

tities and compared. This unit width conversion can be simply performed by dividing the capacitances into the gate-width and multiplying the resistances by the gate-width. The $0.25-\mu \mathrm{m} \mathrm{GaN}$ transistor has a smaller on-resistance than $0.4-\mu \mathrm{m} \mathrm{GaN}$ transistor per millimeter, even though they have similar capacitances. The effect of this difference is analyzed in the next section by simulating with the structures of CMCD and CMCS PA.

\section{CHARACTERISTICS OF CMCD AND CMCS PAs}

The class-S power amplifier consists of a band-pass delta sigma modulator, SMPA, band-pass filter, and balun. Fig. 8 shows the spectra and waveforms of the conventional class-S system according to the each stage. In the constituent of class-S PA, SMPA is the most important part and has some required conditions, such as broad-band matching, push-pull operation, and high-speed switching ability. This SMPA must be enabled to 
operate at a higher frequency range for the over sampling ratio (OSR) needed to generate the pulse waveform.

Two different structures, generally called current-mode and voltage-mode and derived from the conventional class-D amplifier, are suitable for the SMPA. For a high power operation, when compared to the voltage-mode, the current-mode operation has several advantages of including the elimination of drainsource capacitance, simple driver circuitry, and the convenience of using the transistor without considering a stacked structure. Therefore, in this section, transistors with gate-lengths of $0.4-\mu \mathrm{m}$ and $0.25-\mu \mathrm{m}$ and similar output power characteristics, and with gatewidths of $7.2 \mathrm{~mm}$ and $4.8 \mathrm{~mm}$, respectively, are evaluated by simulation on the structure of a CMCD PA.

\section{CMCD PA Simulation at $955 \mathrm{MHz}$}

A simple schematic for the CMCD PA for simulation is shown in Fig. 9. The simplified switch-based models of $\mathrm{GaN}$ transistors with two different gate-lengths of $0.4-\mu \mathrm{m}$ and $0.25-$ $\mu \mathrm{m}$ are used at the position of $Q_{1}$ and $Q_{2}$ to estimate the performance of the transistor as the CMCD PA structure. These models are extracted for the condition where the desired bias voltage and frequency are $10 \mathrm{~V}$ and $955 \mathrm{MHz}$, respectively. The simplified switch-based model is verified by also employing behavioral models of the same transistors in this simulation.

The pulse input signals corresponding to $955 \mathrm{MHz}$ are complementarily injected to each transistor and enabled PA to the push-pull operation. The input signals are amplified efficiently through the switching transistors, and the final RF signal is extracted from the amplified output pulse signal by using the parallel LC resonator. The LC resonator sets a resonance frequency to an operating frequency, and thereby harmonics are filtered and adequately terminated. From the simulation at the input pulse signal of $955 \mathrm{MHz}$, the result of the simplified switch-based model shows a good agreement with that of the behavioral model from the perspective of output power and drain

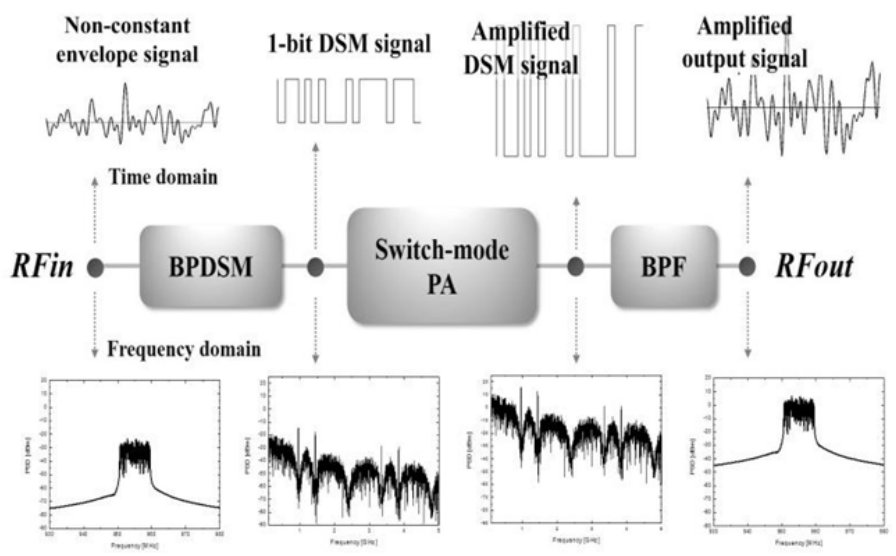

Fig. 8. Spectra and waveforms of the conventional class-S system according to the each stage. BPDSM = band-pass delta-sigma modulation, $\mathrm{PA}=$ power amplifier, $\mathrm{BPF}=$ band-pass filter.

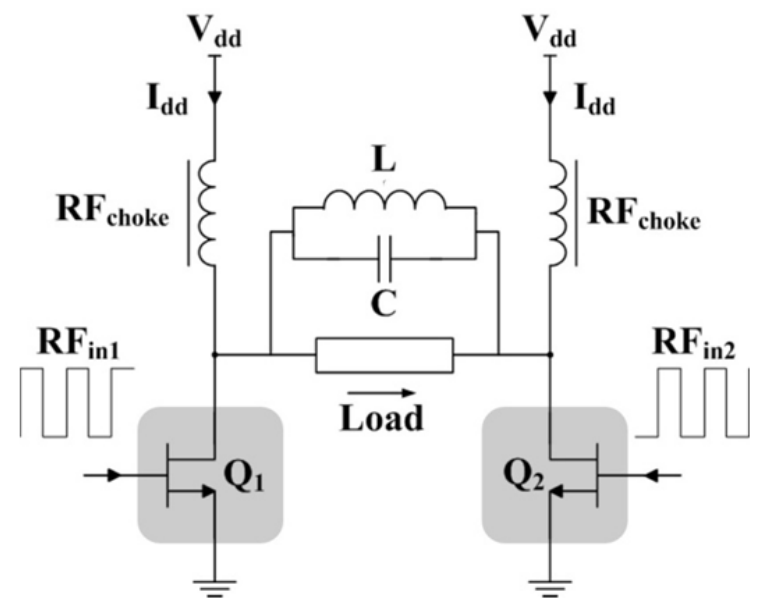

Fig. 9. Schematic of current-mode class-D power amplifier (CMCD $\mathrm{PA})$ for simulation.

Table 3. Characteristics of CMCD PA using the simplified switchbased model and behavioral model of $\mathrm{GaN}$ transistors with a gate-length of $0.4-\mu \mathrm{m}$ and $0.25-\mu \mathrm{m}$ at $955 \mathrm{MHz}$

\begin{tabular}{|c|c|c|c|c|}
\hline \multirow[b]{2}{*}{ Simulated model } & \multicolumn{2}{|c|}{$L_{g}=0.4-\mu \mathrm{m}$} & \multicolumn{2}{|c|}{$L_{g}=0.25-\mu \mathrm{m}$} \\
\hline & $\begin{array}{c}P_{\text {out }} \\
(\mathrm{dBm})\end{array}$ & $\begin{array}{l}\mathrm{DE} \\
(\%)\end{array}$ & $\begin{array}{c}P_{\text {out }} \\
(\mathrm{dBm})\end{array}$ & $\begin{array}{l}\mathrm{DE} \\
(\%)\end{array}$ \\
\hline $\begin{array}{c}\text { Simplified switch- } \\
\text { based model }\end{array}$ & 41.39 & 83.62 & 39.53 & 79.86 \\
\hline Behavioral model & 41.13 & 83 & 39.04 & 78.1 \\
\hline
\end{tabular}

CMCD PA=current-mode class-D power amplifier, $\mathrm{GaN}=$ gallium nitride, $\mathrm{DE}=$ drain efficiency.

efficiency. Although a short gate-length transistor is advantageous at high frequency operation as shown in the previous section, the $0.4-\mu \mathrm{m}$ GaN transistor in the CMCD PA structure shows a better efficiency at $955 \mathrm{MHz}$ owing to the low on-resistance. Table 3 describes the characteristics of the CMCD PA structure using the simplified switch-based model and behavioral model at $955 \mathrm{MHz}$. Note that when the pulse signal is applied at the input of the transistor, the power is lost in charging and discharging the input capacitor. Although this factor has to be considered in the design of the CMCD PA, it is minimized in this simulation by assuming low input resistance to prevent distortion of pulse signal. Therefore, two limitations at the input of the transistor, namely broadband and low resistance, have to be considered in the fabrication of the CMCD PA.

\section{CMCS PA Simulation at $955,2,600$, and $3,500 \mathrm{MHz}$}

The non-constant RF input signal is converted into a 1-bit random pulse-width modulated signal by the BPDSM, which enables the SMPA to perform the push-pull operation. The CMCS PA amplifies the differential BPDSM input signal, and due to the pulse shaped BPDSM input signal, the PA is required to have broadband characteristics up to several times the operating frequency, which is called OSR. The frequency component 


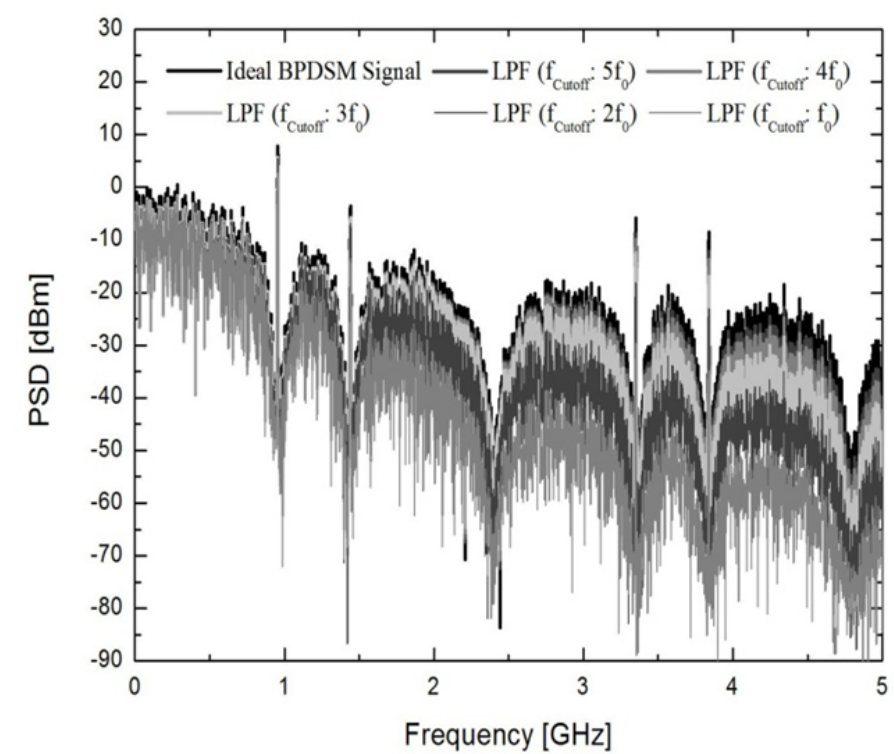

(a)

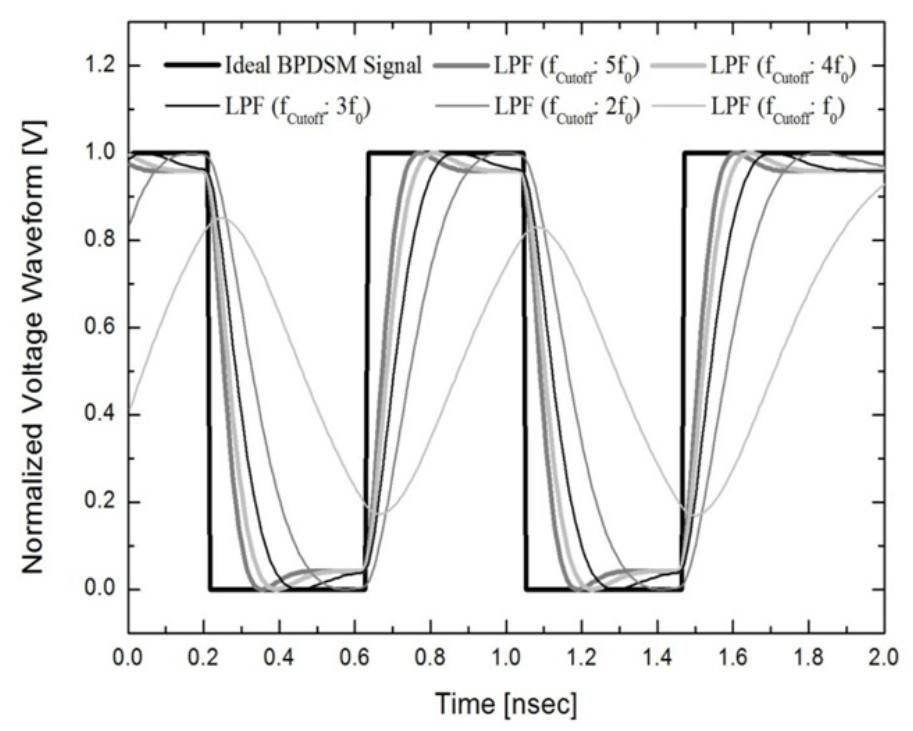

(b)

Fig. 10. The variation of band-pass delta-sigma modulation (BPDSM) signal according to the upper cutoff frequency by assuming the system as low-pass filter (LPF). (a) Spectra and (b) waveforms. $\mathrm{PSD}=$ power spectral density.

of the pulse is composed of fundamental frequency and harmonics, which result in quantization noise components of the BPDSM signals. The quantization noise levels are important to sustain BPDSM signal, and the shape of pulse directly influences the output power and efficiency of the class-S PA.

Fig. 10 shows the variations of spectra and waveforms of the BPDSM signal according to the upper cutoff frequency by assuming the bandwidth of the PA as a low-pass filter. That is, this graph illustrates the impact of high frequency harmonic components on the waveforms. When harmonic components are included as frequently as possible, the BPDSM signal can be similar to the ideal pulse signal. Therefore, at a minimum, the transistor for a CMCS PA has to have a gain until a frequency is reached

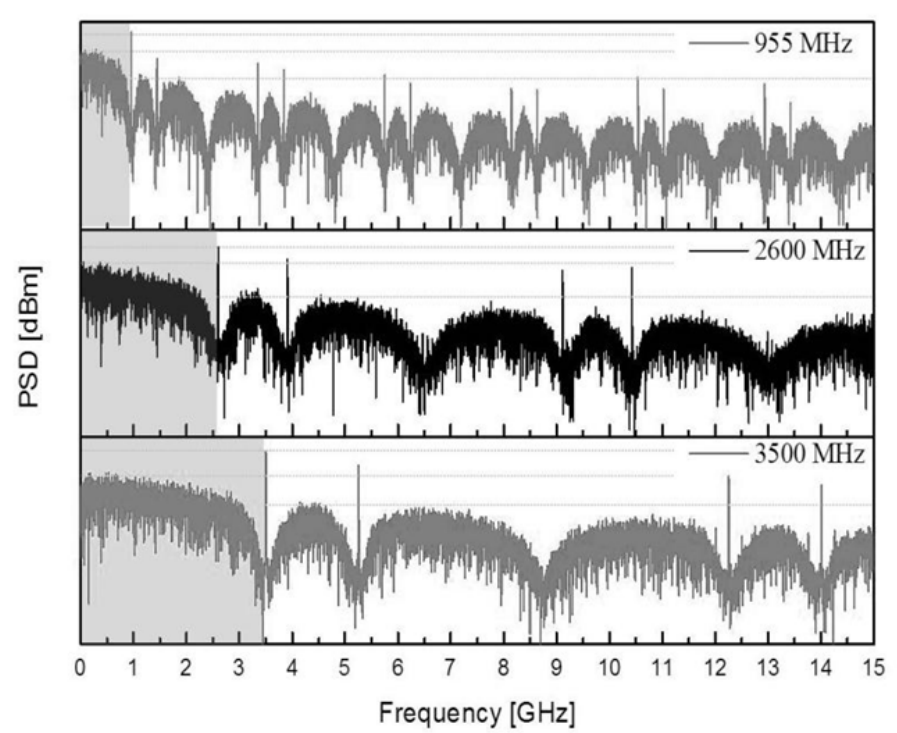

Fig. 11. Power spectral density of BPDSM output signal using LTE waveforms at the center frequency of $955,2,600$, and 3,500 MHz. $\mathrm{BPDSM}=$ band-pass delta-sigma modulation, $\mathrm{PSD}=$ power spectral density.

Table 4. Simulated characteristics of CMCS PA applying a BPDSM input signal using $\mathrm{GaN}$ transistors with a gate-length of 0.4$\mu \mathrm{m}$ and $0.25-\mu \mathrm{m}$ at three operating frequencies

\begin{tabular}{cccccc}
\hline \multirow{2}{*}{$\begin{array}{c}\text { Frequency } \\
(\mathrm{MHz})\end{array}$} & \multicolumn{2}{c}{$L_{g}=0.4-\mu \mathrm{m}$} & & \multicolumn{2}{c}{$L_{g}=0.25-\mu \mathrm{m}$} \\
\cline { 2 - 3 } \cline { 6 - 7 } & $\begin{array}{c}P_{\text {out }} \\
(\mathrm{dBm})\end{array}$ & $\begin{array}{c}\mathrm{DE} \\
(\%)\end{array}$ & & $\begin{array}{c}P_{\text {out }} \\
(\mathrm{dBm})\end{array}$ & $\begin{array}{c}\mathrm{DE} \\
(\%)\end{array}$ \\
\hline 955 & 41.66 & 49.01 & & 40 & 43.46 \\
2,600 & 38.4 & 22.28 & & 37.61 & 22.42 \\
3,500 & 36.64 & 14.66 & & 38.59 & 16.96 \\
\hline
\end{tabular}

CMCD PA = current-mode class-D power amplifier, BPDSM = bandpass delta-sigma modulation, $\mathrm{GaN}=$ gallium nitride, $\mathrm{DE}=$ drain efficiency.

that is three or four times the operating frequency.

A simulation of the conventional CMCS PA, applying a BPDSM input signal of $8.5 \mathrm{~dB}$ PAPR 3G LTE $10 \mathrm{MHz}$ at three operating frequencies of $955,2,600$, and 3,500 $\mathrm{MHz}$ reveals that the characteristics of the PA using $0.4-\mu \mathrm{m}$ and $0.25-\mu \mathrm{m}$ $\mathrm{GaN}$ transistors can be expected considering the effect of the upper frequency limit of the transistor. Fig. 11 describes the BPDSM input signals with center frequency of 955, 2,600, and $3,500 \mathrm{MHz}$, and Table 4 is a summary of the simulated characteristics of the CMCS PA at three operating frequencies in terms of an average output power and efficiency. The $955 \mathrm{MHz}$ is the desired frequency in this work, and both transistors having two different gate-lengths are available in the CMCS PA considering OSR and compared with each other. The other operating frequencies, 2,600 and 3,500 $\mathrm{MHz}$, are also selected among the LTE frequencies to evaluate the characteristics of transistor according to the higher harmonics. As shown in Fig. 5, the $0.4-\mu \mathrm{m}$ transistor does not operate as efficiently as the 0.25 $\mu \mathrm{m}$ transistor at higher frequency region and this trend is well 
reflected in Table 4. However, although the efficiency of the 0.4$\mu \mathrm{m}$ transistor decreases to a greater extent as the operating frequency increases from 955 to $3,500 \mathrm{MHz}$ due to the efficiency limitation at the higher frequency region, it shows better efficiency (as much as $5.5 \%$ ) at $955 \mathrm{MHz}$ compared to $0.25-\mu \mathrm{m}$ transistor. Therefore, an adequate transistor has to be selected depending on desired operating frequency and its harmonics, and the $0.4-\mu \mathrm{m} \mathrm{GaN}$ transistor is more advantageous in the design of CMCS PA compared to the $0.25-\mu \mathrm{m}$ transistor at $955 \mathrm{MHz}$. Note that these results are caused by the different gate-width of each commercial transistor with two gate-lengths for the desired output power. In fact, if the gate-width is identical, the transistor having a short gate-length will show better efficiency even at 955 MHz.

Based on the above analysis, we previously proposed two types of current-mode PAs, which are push-pull inverse class-F PA [22] and hybrid current-mode class-D PA [23]. In those papers, PAs attained a high efficiency (over 77\%) in the frequency range of 3.3 GHz. In addition, a hybrid CMCS PA was also proposed using the chip-on-board technique for the $955 \mathrm{MHz}$ LTE signal and showed an efficiency of $38.5 \%$ at the average power [24].

\section{CONCLUSION}

This paper describes a process for the selection of an adequate transistor among the commercial $\mathrm{GaN}$ transistors having two different gate-lengths for class-S PA design. First, the basic characteristics of the $\mathrm{GaN}$ transistor with two gate-lengths of $0.4-\mu \mathrm{m}$ and $0.25-\mu \mathrm{m}$ are analyzed by extracting $f_{T}, f_{\max }$, and using a simplified switch-based model. In addition, the performance characteristics are also described and compared using CMCD and CMDS PA structures. Although the efficiency of the CMCS PA with a $0.4-\mu \mathrm{m} \mathrm{GaN} \mathrm{transistor} \mathrm{rapidly} \mathrm{decreases} \mathrm{at} \mathrm{3,500}$ $\mathrm{MHz}$, a similar performance can be obtained at $955 \mathrm{MHz}$. In fact, the conventional class-S PA cannot operate efficiently over about $1 \mathrm{GHz}$ due to the limitation of coding efficiency of the BPDSM. Therefore, the $0.4-\mu \mathrm{m}$ GaN transistor is sufficient for the design of a class-S PA compared to $0.25-\mu \mathrm{m} \mathrm{GaN}$ transistor at $955 \mathrm{MHz}$. This analysis can be utilized in designing a class-S PA for a $955 \mathrm{MHz}$ LTE signal.

This research was supported by the Ministry of Science, ICT and Future Planning (MSIP), Korea, under the Convergence Information Technology Research Center (C-ITRC) support program supervised by the National IT Industry Promotion Agency (No. NIPA-2014-H0401-14-1007).

\section{REFERENCES}

[1] M. Iwamoto, A. Williams, P. F. Chen, A. G. Metzger, L. E.
Larson, and P. M. Asbeck, "An extended doherty amplifier with high efficiency over a wide power range," IEEE Transactions on Microwave Theory and Techniques, vol. 49, no. 12, pp. 2472-2479, Dec. 2001.

[2] B. Kim, J. Kim, I. Kim, and J. Cha, "The Doherty power amplifier," IEEE Microwave Magazine, vol. 7, no. 5, pp. 4250, Oct. 2006.

[3] J. C. Park, D. Kim, C. S. Yoo, W. S. Lee, J. G. Yook, and C. K. Hahn, "Efficiency enhancement of the Doherty amplifier for $3.5 \mathrm{GHz}$ WiMAX application using class-F circuitry," Microwave and Optical Technology Letters, vol. 52, no. 3, pp. 570-573, Mar. 2010.

[4] J. C. Park, D. Kim, C. S. Yoo, W. S. Lee, J. G. Yook, S. H. Chun, J. H. Kim, and C. K. Hahn, "GaN HEMT based high power and high efficiency Doherty amplifiers with digital pre-distortion correction for WiBro applications," Journal of the Korea Electromagnetic Engineering Society, vol. 11, no. 1, pp. 16-26, Mar. 2011.

[5] J. J. Yan, C. D. Presti, D. F. Kimball, Y. P. Hong, C. Hsia, P. M. Asbeck, and J. Schellenberg, "Efficiency enhancement of mm-wave power amplifiers using envelope tracking," IEEE Microwave and Wireless Components Letters, vol. 21, no. 3, pp. 157-159, Mar. 2011.

[6] F. Wang, A. H. Yang, D. F. Kimball, L. E. Larson, and P. M. Asbeck, "Design of wide-bandwidth envelope-tracking power amplifiers for OFDM applications," IEEE Transactions on Microwave Theory and Techniques, vol. 53, no. 4, pp. 1244-1255, Apr. 2005.

[7] F. Wang, D. F. Kimball, J. D. Popp, A. H. Yang, D. Y. Lie, P. M. Asbeck, and L. E. Larson, "An improved power-added efficiency $19-\mathrm{dBm}$ hybrid envelope elimination and restoration power amplifier for 802.11g WLAN applications," IEEE Transactions on Microwave Theory and Techniques, vol. 54, no. 12, pp. 4086-4099, Dec. 2006.

[8] S. S. Myoung, I. K. Lee, J. G. Yook, K. Lim, and J. Laskar, "Mismatch detection and compensation method for the LINC system using a closed-form expression," IEEE Transactions on Microwave Theory and Techniques, vol. 56, no. 12, pp. 3050-3057, Dec. 2008.

[9] A. Jayaraman, P. F. Chen, G. Hanington, L. Larson, and P. Asbeck, "Linear high-efficiency microwave power amplifiers using bandpass delta-sigma modulators," IEEE Microwave Guides Wave Letter, vol. 8, no. 3, pp. 121-123, Mar. 1998.

[10] M. Iwamoto, A. Jayaraman, G. Hannington, P. F. Chen, A. Bellora, W. Thornton, L. E. Larson, and P. M. Asbeck, "Bandpass delta-sigma class-S amplifier," Electronics Letters, vol. 36, no. 12, pp. 1010-1012, Jun. 2000.

[11] F. Schwierz and O. Ambacher, "Recent advances in GaN HEMT development," in Proceedings of the 11th IEEE International Symposium on Electron Devices for Microwave and 
Optoelectronic Applications, Orlando, FL, 2003, pp. 204-209.

[12] T. Ohki, T. Kikkawa, Y. Inoue, M. Kanamura, N. Okamoto, K. Makiyama, K. Imanishi, H. Shigematsu, K. Joshin, and N. Hara, "Reliability of GaN HEMTs: current status and future technology," in Proceedings of the IEEE International Reliability Physics Symposium, Montreal, Canada, 2009, pp. 61-70.

[13] J. H. Kim, G. D. Jo, J. H. Oh, Y. H. Kim, K. C. Lee, and J. H. Jung, "Modeling and design methodology of high efficiency class-F and class- $\mathrm{F}^{-1}$ power amplifiers," IEEE Transactions on Microwave Theory and Techniques, vol. 59, no. 1, pp. 153-165, Jan. 2011.

[14] D. Kimball, P. Draxler, J. Jeong, C. Hsia, S. Lanfranco, W. Nagy, K. Linthicum, L. Larson, and P. Asbeck, "50\% PAE WCDMA base-station amplifier implemented with $\mathrm{GaN}$ HFETs," in Proceedings of the Compound Semiconductor Integrated Circuit Symposium, Palm Springs, CA, 2005, pp. 89-92.

[15] P. Wright, J. Lees, J. Benedikt, P. J. Tasker, and S. C. Cripps, "A methodology for realizing high efficiency class-J in a linear and broadband PA," IEEE Transactions on Microwave Theory and Techniques, vol. 57, no. 12, pp. 31963204, Dec. 2009.

[16] Y. S. Lee, M. W. Lee, and Y. H. Jeong, "High-efficiency class-F GaN HEMT amplifier with simple parasitic-compensation circuit," IEEE Microwave and Wireless Components Letters, vol. 18, no. 1, pp. 55-57, Jan. 2008.

[17] M. W. Lee, Y. S. Lee, and Y. H. Jeong, "A high-efficiency GaN HEMT hybrid class-E power amplifier for $3.5 \mathrm{GHz}$ applications," in Proceedings of the 38th European Microwave Conference, Amsterdam, 2008, pp. 436-439.

[18] R. Negra, T. D. Chu, M. Helaoui, S. Boumaiza, S. Hegazi,

Jun-Chul Park

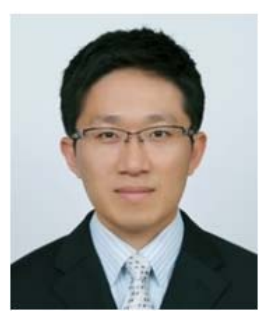

was born in Jinhae, Korea. He received B.S. and M.S. degrees in electrical and electronic engineering from Yonsei University, Seoul, Korea, in 2007, and 2009, respectively, and is currently working toward a Ph.D. degree at Yonsei University. Since 2007, he has been an assistant researcher at the Electronic Materials \& Device Research Center of Korea Electronics Technology Institute in Korea. His current research interests include GaN-based transistor modeling and analysis, high power amplifiers, high-efficiency switch-mode power amplifiers, broad-band power amplifiers, and communication system design and analysis. suitable for highly-efficient RF power amplifier design," in Proceedings of the IEEE MTT-S International Microwave Symposium Digest, Honolulu, HI, 2007, pp. 795-798.

[19] I. Angelov, K. Andersson, D. Schreours, D. Xiao, N. Rorsman, V. Desmaris, M. Sudow, and H. Zirath, "Largesignal modeling and comparison of AlGaN/GaN HEMTs and $\mathrm{SiC}$ MESFETs," in Proceedings of the Asia-Pacific Microwave Conference, Yokohama, Japan, 2006, pp. 279-282.

[20] N. Chevaux and M. M. Souza, "Class-D power amplifiers using LDMOS and GaN power devices: a comparative analysis," in Proceedings of the 15th IEEE Mediterranean Electrotechnical Conference, Valletta, 2010, pp. 691-694.

[21] G. Dambrine, A. Cappy, F. Heliodore, and E. Playez, "A new method for determining the FET small-signal equivalent circuit," IEEE Transactions on Microwave Theory and Techniques, vol. 36, no. 7, pp. 1151-1159, Jul. 1988.

[22] J. C. Park, C. S. Yoo, W. Kang, D. Kim, J. G. Yook, and W. S. Lee, "GaN HEMT based high efficiency push-pull inverse class-F power amplifier using chip-on-board technique," in Proceedings of the Asia-Pacific Microwave Conference, Melbourne, 2011, pp. 522-525.

[23] J. C. Park, C. S. Yoo, W. Kang, D. Kim, J. G. Yook, and W. S. Lee, "GaN HEMT based high-efficiency current-mode class-D amplifier using chip-on-board technique," Microwave and Optical Technology Letters, vol. 54, no. 2, pp. 358362, Feb. 2012.

[24] J. C. Park, J. G. Yook, B. H. Park, N. Jeon, K. S. Seo, D. Kim, W. S. Lee, and C. S. Yoo, "Hybrid current-mode class-S power amplifier with GaN Schottky diode using chip-on-board technique for $955 \mathrm{MHz}$ LTE signal," IEEE Transactions on Microwave Theory and Techniques, vol. 61, no. 12, pp. 4168-4178, Dec. 2013.

Chan-Sei Yoo

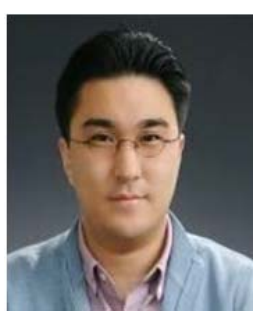

received the B.S. and M.S. degrees in electrochemical engineering in 1996 and 1998, respectively and $\mathrm{Ph}$. D. degree in electronic and electrical engineering in 2010 from Seoul National University, Seoul, Korea. In 1998, he joined the Electronic Materials \& Device Research Center at Korea Electronics Technology Institute, Korea, where he was involved in the development of microwave chip component using LTCC technology such as chip inductor, chip capacitor, chip coupler and chip balun and so on. And then he has conducted research on the ceramic module like dual-band voltage controlled oscillator for GSM/DCS application, dual-band antenna switch module for GSM/DCS application, and dual-band power amplifiers for KPCS/WCDMA and GSM/WCDMA applications. His current research focuses the UltraWideBand transceiver modules, the radar systems for mmWave application and the high power and high efficiency amplifiers including switch mode operation. 


\section{Dongsu Kim}

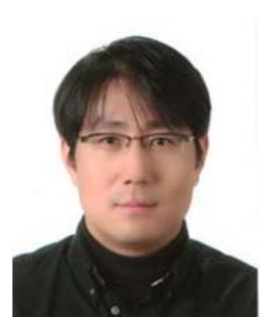

received the B.S. and M.S. degrees in electronic and electrical engineering from Kyungpook National University, Daegu, Korea, in 1997 and 1999, respectively, and M.S. and Ph.D. degrees in electrical and computer engineering from the Georgia Institute of Technology, Atlanta, USA, in 2001 and 2004, respectively. In 2001, he was with MicroCoating Technologies, Chamblee, GA, where he was involved with design and analysis of ferroelectric tunable devices. Since 2004, he has been with the Packaging Research Center, Korea Electronics Technology Institute (KETI), where he has conducted research in RF passive components and modules. He has authored or co-authored more than 100 journal and conference papers. His current research interests include microwave passive components, LTCC-, PCB-based multilayer modules, Si interposer with IPD and TSV, and high-efficiency power amplifiers.

\section{Woo-Sung Lee}

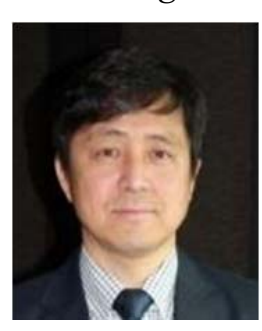

received the B.S. and M.S., and Ph.D. degrees in material science engineering from Korea University, Seoul, Korea, in 1990, 1992, and 2008, respectively. In 1992, he joined Yuyu co., Seoul, Korea, where he was involved in the development of magnetic materials for switching mode power supply and magnetic strip sensor. In 1997, he has joined KETI, Korea Electronic Technology Institute, where he has been involved in the research and development activities for microwave devices using LTCC and polymer-ceramic materials. His research regions are included the material design and fabrication process of components such as inductor, coupler, PAM, VCO, and UWB module for wireless communication system. He has been with the Department of Electronic Materials \& Devices Research center, he is currently an principal researcher. His major interest is in device technology based on the ceramic-polymer composite and their applications.

\section{Jong-Gwan Yook}

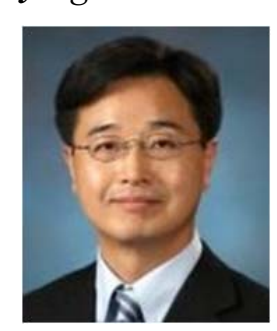

was born in Seoul, Korea. He received the B.S. and M.S. degrees in electronics engineering from Yonsei University, Seoul, Korea, in 1987 and 1989, respectively, and the Ph.D. degree from The University of Michigan, Ann Arbor, MI, in 1996. He is currently a Professor with the School of Electrical and Electronic Engineering, Yonsei University. His main research interests are in the areas of theoretical/numerical electromagnetic modeling and characterization of microwave/millimeter-wave circuits and components, design of radio frequency integrated circuits (RFIC) and monolithic microwave integrated-circuit (MMIC), and analysis and optimization of high-frequency high-speed interconnects, including signal/ power integrity (EMI/EMC), based on frequency as well as time-domain full-wave methods. Recently, his research team is developing various biosensors, such as carbon-nano-tube RF biosensor for nanometer size antigenantibody detection as well as remote wireless vital signal monitoring sensors. 